\title{
The Role of Written Corrective Feedback in Improving Kurdish EFL University Students' Writing
}

\author{
Abbas Mustafa Abbas $^{1} \&$ Hogar Mohammed Tawfeeq $^{1 ’ 2}$ \\ 1 English Department, School of Basic Education, Sulaimani University, Sulaymaniyah, Kurdistan Region - F.R Iraq \\ 2 International English Language Center, Sulaimani Polytechnic University, Sulaymaniyah, Kurdistan Region - F.R Iraq
}

\begin{abstract}
There has been a long debate about the effect of written corrective feedback (WCF) on improving L2 learners' linguistic accuracy in writing. Some scholars question the effectiveness of WCF on improving EFL/ESL learners' linguistic accuracy. However, other researchers argue for the value WCF to the improvement of L2 learners' writing performance. The current paper conducts an experiment aiming to investigate whether or what type of WCF has any short- and long-terms effects on improving learners' linguistic accuracy in writing. The study includes 105 third-year-undergraduate EFL students from the English Department in Iraqi Kurdistan Region's two public universities. The subjects were divided into two main groups: treatment and control. The former was assigned as no corrective feedback group that was merely provided with comments on writing content, and the latter was subdivided into two experimental groups that received either indirect or direct WCF. Data was collected from learner's essays, tests (pretest, posttest and delayed posttest) and treatments (giving WCF). Over a study period of eight weeks, the present research found out statistically significant differences between the writing accuracy of the treatment groups and the control group. The results of this study have some recommendations for future studies and pedagogical implications.
\end{abstract}

Keywords - written corrective feedback, linguistic accuracy, indirect feedback, direct feedback, writing accuracy

\section{INTRODUCTON}

It is thought that producing accurate, coherent and fluent writing is probably the most difficult language skill, even for many native speakers (Almasi \& Tabrizi, 2016; Alimohammadi \& Nejadansari, 2014). Although academic writing process involves various highly complex skills such as planning, organising, coherence and taskresponse, grammatical and lexical accuracy is considered the most significant aspect of assessment criterion for students because of the exam-orientated approach to teaching of writing in many academic settings (Almasi \& Tabrizi, 2016).

Therefore, providing written corrective feedback (WCF) on students' papers is deemed necessary and one of the key responsibilities of L2 writing instructors in such contexts to help students produce more linguistically accurate writings (Wang, 2017). However, how and the extent to which teachers correct student writing have long been a controversial subject to both researchers and teachers in ESL/EFL writing classes (Tootkaboni \& Khatib, 2014)

It is worth mentioning that there are theoretical disputes and conflicting research tendencies between SLA and L2 writing studies regarding the role played by corrective feedback in language acquisition, especially in facilitating L2 writers' development (Tootkaboni \& Khatib, 2014; Ferris, 2010). On the one hand, some scholars postulate that WCF is either unhelpful or even harmful for the learning process and learners' writing development; consequently, they recommend abandoning its practice in L2 writing classroom completely (cf. Truscott, 1996, 1999, 2007). On the other hand, other theorists highly value the efficacy of WCF for developing learners' acquisition process because it promotes their noticing strategy and increases their attention to non-target like language production (e.g. Bower \& Kawaguchi, 2011).

Since Truscott's review article in 1996 in which he held a strong view against the usefulness and effectiveness of all forms of grammar correction in L2 writing, this topic has been given significant attention in several publications in the area of L2 writing and acquisition (Chandler, 2003). In her response, Ferris (1999) rebutted Truscott's notion and maintains that it is entirely premature and based on inconclusive evidence. Responding to students' grammatical and lexical errors deemed necessary to mitigate their concerns over writing accuracy despite the fact that real-life teachers find error correction time-consuming, troublesome and uncertain about its longterm effectiveness.

Thus, Ferris concludes by calling for further methodologically appropriate research to investigate whether error correction is effective and applicable at all, and if so, how to approach it. Drawn from Hendrickson (1978), this is mirrored by Chandler (2003) who implies that further studies on the topic under inquiry are very important and beneficial for researchers and teachers of L2 composition to decide whether, when, which, and how students' errors should be corrected, particularly grammatical and lexical errors. Although many scholars have recently made endeavors to reach conclusive answers to the above-mentioned questions, yet the literature on the role of corrective feedback in ESL/EFL writing is speculative and relatively scant.

The current paper has brought to light some significant aspects of corrective feedback that could be insightful for both ESL/EFL writing researchers and real-life practitioners. However, few studies to date have investigated the role of WCF in facilitating Kurdish EFL learners' writing accuracy (cf. Hama \& Ismael, 2018). The findings

Journal of University of Human Development

Volume 4 No4(2018); DOI: 10.21928/juhd. v4n4y2018.pp61-74

Regular research paper :(14) Received 30 July 2018; Accepted 30 August 2018; Published 10 December 2018

Corresponding author's e-mail: hogar.tawfeeq@spu.edu.iq

Copyright (c) 2018 Abbas Mustafa Abbas \& Hogar Mohammed Tawfeeq. This is an open access article distributed under the Creative

Commons Attribution License (CC BY-NC-ND 4.0) 
of their study conducted in 2016 on eighty third-year undergraduates from the College of Basic Education of Sulaimani University show that WCF was perceived to be important to be provided by teachers to improve grammatical, punctuation, and style of essay writing. Though the outcome of this survey-based paper seems informative and insightful to EFL or ESL writing teachers and scholars, other empirical written data and error analysis of direct composition would be needed to ensure the pedagogical implications and generalizability of the findings across EFL settings.

Noticeably, the results of recent SLA and L2 writing studies have shed some light on how and the extent to which WCF is useful in second and foreign language; however, they are questioned for their theoretical paradigm (Diab, 2015; Ferris, 2010) and research design issues (e.g. Liu \& Brown, 2015). Understanding recent studies' methodological limitations such as lack of control group and conflicting methodologies between SLA and L2 writing research, the purpose of this study is to examine potential and differential effectiveness of WCF arising in Kurdish EFL writing instructional settings by adopting a blended research design (Liu \& Brown, 2015) or intersection between SLA and L2 writing research paradigm.

This research gap has long been observed by Ferris (1999) who calls for "urgent need for new research efforts which utilize a variety of paradigms to examine a range of questions that arise around this important topic', (p. 2). As Chandler (2003) points out, despite their different positions, it is implied that both Truscott and Ferris are in agreement that the existing data are insufficient to answer the main questions of whether WCF can be helpful to promote ESL or EFL students' accuracy in writing and if so, how teachers should correct students' errors in writing (Wang, 2017; Tootkaboni \& Khatib, 2014).

Given that, the current research attempts to present empirical data to examine the differential effect of teacher WCF by combining experimental design on WCF together with requiring participants to revise their essays (Liu \& Brown, 2015). It also compares the shortterm ad long-term improvement in overall writing accuracy in the treatment group during an experimental study in which the researcher marked grammatical, lexical and mechanical errors in each essay prior to producing the subsequent writing with that in a control group.

To this end, the current article reviews some definitions concerning corrective feedback, followed by a theoretical overview of a considerable body of research on the argument for and against the role WCF plays in improving writing, particularly written accuracy in English as a second or foreign language. The research methodology is then described, and the results and discussion of the study will be presented.

\section{LITERATRE REVIEW}

Since the definition of corrective feedback (CF) varies among researchers, it is important to clarify how the term is used in this paper. Previous studies employed corrective feedback (CF) to describe negative evidence in second language acquisition (SLA); and thereafter, it has been used interchangeably with grammar correction or error correction by other scholars (cf. Truscott, 1996, 1999).

The term is also defined as any feedback that shows the learner's language-related issues (Russell and Spada, 2006), and refers to grammatical forms (Wang, 2017). In this study, we shall use the terms 'error correction', 'error feedback' and 'corrective feedback' interchangeably to refer to WCF on lexical, grammatical, and mechanical errors to analyze the sentence-level accuracy of writing.

Over the past decades, there has been a considerable debate on whether WCF in L2 writing can improve students' written accuracy. In the process-orientated approach to teaching of writing, a reader's (e.g. a teacher) feedback on the high-level issues of writing such as the content and organization is first placed emphasis, followed by grammatical accuracy which is left to the final editing stage.

Promoters of the approach have frequently said that explicit WCF is highly likely to impede the development of fluency in writing (Semke, 1984; Zamel, 1985). Some other previous studies did not show significant effects of teacher's WCF on improving written accuracy of L2 students in comparison with no feedback group or group that received only comments about content-related issues (cf. Sheppard, 1992; Kepner, 1991; Polio, Fleck, \& Leder, 1998).

Consider Kepner's (1991) experimental study, which responded to a linguistically diverse group of twenty-six undergraduate students' errors in writing in two ways: error feedback on surface-level issues and holistic feedback on content-related problems. It was found that content-related holistic comments resulted in improvements of overall writing quality as well as in grammatical accuracy.

In contrast, surface error-correction was reported to be ineffective. However, many writers have challenged Kepner's claim on the grounds that it does not attempt to assess the effectiveness of error correction by engaging students to produce a new piece of writing incorporating the teachers' responses (e.g. Chandler, 2003). As Liu (2008) maintains, another problem with this study is that it fails to take into account that surface error-corrections targeted merely the sentence-level concerns; therefore, it cannot make noticeable improvement in the content-based aspects of writing by analogy with holistic feedback that is concerned more with the high-level issues of writing.

Likewise, Zamel's (1985) experimental research reports no significant difference in enhancing grammatical accuracy of students' composition between grammar correction group and content-based feedback group. On the contrary, students who were given feedback on only the content of writing outperformed those who were given grammar correction only. This outcome is in line with Semke' (1984) findings from a 10-week experimental study grouping L2 German students into four groups that had been provided with: comments on grammatical errors; comments on content; comments on both grammar and content; and marking errors without correction by adopting a process approach.

Based on the study, Semke urges teachers to emphasize more on content-related concerns than WCF on grammar because she found out error correction did not lead to more written accuracy of the grammar correction students. This line of research was strongly supported by Truscott $(1996,1999,2004,2007)$ who claims that WCF is not only impractical but also harmful to students' written accuracy. His analysis was mainly driven from the above-mentioned studies that led to the conclusion that error correction never assists learners to increase their writing accuracy.

According to Bitchener, Young, and Cameron (2005), Truscott had 
two major reasons that justify his finding. The first reason, as he contended, was that error correction practices fail to notice SLA perspectives on a second language's gradual and complex nature of acquiring the forms and structures. The other reason lies in a range of impracticality and time-consuming process of error correction on the part of teachers to give and unwillingness of students to work out the teacher's responses. This implies that WCF is harmful because it takes much time and energy that can be spent on other learning aspects of a language classroom.

Considering the communicative aspect of writing, results from Semke (1984) and Zamel's (1985) studies could be insightful for L2 writing instructors to be more concerned with the content of writing than with surface-level issues. Nevertheless, the findings concerning the role of error correction in improving sentence-level grammatical concerns in composition must be interpreted cautiously.

As Hong (2004) hypothesizes, Semke's argument about the ineffectiveness of error correction and harmful impact on fluency cannot be entirely attributed to the different treatment methods but also to differences in the quantity of writing practice. Namely, the groups provided with corrections alone or corrections and holistic feedback were assigned to produce half as many written texts as the content-related feedback group because of the time spent on revisions, and the self-editing group undertook fewer new written tasks.

Although the error correction group did not outperform the other groups in the post-test, the finding of this study may not be interpreted to mean that error correction had no merits for long-term accuracy development of the students in writing (cf. Chander, 2003).

Similarly, Polio et al.'s (1998) claims have been strongly contested in recent years by other writers (cf. Chander, 2003) because the control group was required to write twice as many journal entries as the error correction treatment group because of their self-correcting activities. The findings from this study, however, show that even though no significant difference found between the two groups was made, their written accuracy improved by the end of the study.

In contrast to the opponents of WCF, several scholars (cf. Hyland, 2003; Chandler, 2003; Lee, 2005; Bitchner, 2008; Bruton, 2010; Bitchnener and Knoch, 2008, 2010) argue in favour of the positive contribution of teacher's error feedback to a consistent learning process, especially to students' improved accuracy in L2 learners' written texts. Additionally, a growing number of L2 researchers assert that the language classroom instruction should incorporate corrective feedback because it facilitates L2 learning process (Wang, 2017).

One of the prominent proponents of grammar correction is Ferris (1999) who evaluated Truscott's notions of the futility of error corrections and depicted Truscott's grammar correction claims as premature and unconvincing. According to Ferris, though error correction is a debated issue for both writing teachers and scholars, it has been beneficial for many of her students who have made great improvements in their accuracy of writing.

Having believed the result at least in short-term learning outcomes and its likelihood of long term improvements, she urges writing practitioners to continue the practice of grammar correction due to some reasons. As Ferris says, the first reason is that writing

JUHD | https://doi.org/10.21928/juhd. v4n4y2018.pp61-74 accurately is a great concern to students who expect to receive correction from teachers; therefore, several writing-based grading scheme plainly show that grammatical errors refrain students from obtaining high marks in writing proficiency exams. Hence, grammar correction is considered to be positively affecting students' motivation and confidence in their writing. Secondly, proper provision of writing corrective feedback raises students' metalinguistic awareness to self-correct their own written essays. Thirdly, many college teachers are very intolerant of students' errors, which affect the overall assessment of their exam papers (Ferris, 1999, 2004, 2010).

Regarding the importance of WCF in the long-term, many researchers also point out that error feedback can help L2 students produce more accurate texts than those who do not receive it (Wang, 2017). With constant improvements in accuracy, corrective feedback results in the development of ESL/EFL students' overall language proficiency overtime. Thus, explicit error feedback can particularly assist the adult ESL students to significantly drop the possibility of fossilization during their second language acquisition (Polio, 2012; Shintani, Ellis \& Susuki; 2014, Kang \& Han, 2015). Therefore, it seems clear that exposing L2 students to explicit corrective feedback helps them realise why they make errors and how to overcome them.

Some other studies confirm Ferris's proposition by showing positive results in the benefit of corrective feedback to improve the students' accuracy in written essays. Hyland (2003) showed that teachers' form-focused feedback on L2 learners leads to improvement in their writing because most of them highly valued and used the feedback in their immediate revisions to their drafts. This study was conducted on six ESL writers over a 14-week university-level English proficiency course. The, study claims that using teachers' feedback might be useful to treat some language errors.

Recalling this, Chandler's (2003) data from an experimental-control designed study demonstrates that both students' accuracy and fluency in following writing of the same type over a semester were improved significantly through teachers' CF on their grammatical and lexical errors. It could be argued with Liu (2008) that this result invalidates Truscott's (1999) strong belief about the negative impact of WCF on students' writing, especially grammatical errors.

Recent studies have investigated how and what error types should be chosen for corrections (Chandler, 2003; Bitchener, 2008; Bitchener et al 2005; Abedi \& Latifi, 2010; Hosseiny, 2014; Shintani, Ellis \& Suzuki, 2014; Eslami, 2014; Jamalinesari, Rahimi, Gowhary \& Azizifar, 2015). They have mostly attempted to explore the distinction between direct and indirect WCF. Ferris (2011) defined direct corrective feedback (DCF) as one "when an instructor provides the correct linguistic form for students (word, morpheme, phrase, rewritten sentence, deleted word[s] or morpheme[s]" (p.31).

On the other hand, indirect corrective feedback (ICF) taking the form of underlining and coding (or description) of the errors "occurs when the teacher indicates that an error has been made but leaves it to the student writer to solve the problem and correct the error" (Ferris, 2011, p.32).

Hosseiny (2014)' study on 60 pre-intermediate EFL students in an Iranian institute in Ardabil investigated the effect of DCF and ICF on improving their writing skills. The students were tested about definite and indefinite articles in five sessions (one session per week). Their errors were treated differently based on their group types: direct, 
indirect and control (no feedback). The papers of DCF group were given direct correction of errors, but underlining the errors on the papers of ICF group. The results revealed that the both groups outperformed the control group.

Supporting this result, Shintani, Ellis \& Suzuki's (2014) study compared the effectiveness of the form-focused written feedbackdirect feedback and metalinguistic explanation both with and without an opportunity to rewrite - on 214 Japanese college students' written accuracy of use of two linguistic features: the hypothetical conditional and indefinite article. They found that DCF with the opportunity to revise proved the most effective type of feedback on enhancing accuracy in new pieces of writing for the hypothetical conditional but not for the indefinite article.

The study concludes that the DCF led to longer lasting improvement than the metalinguistic explanation in accuracy possibly because it exposed the participants to both negative and positive evidence on the errors they had made. The results also reveal that student writers probably concentrate on the complex syntactical grammatical structures that affect more the global meaning of the text.

Challenging this outcome, Eslami (2014) found that the ICF was more effective than DCF for both short- and long terms. The results were based on a study involving 60 low-intermediate EFL students in Karaj (an Iranian city) who were assigned into two different CF groups-ICF group and DCF group. The students on the DCF group were provided with the direct red pen correction, while the participants on the other group were given an indirect technique. The students' accuracy use of simple past tense was tested in three pieces of writing (pre-test, immediate post-test, and delayed post-test).

Corroborating this view, Abedi \& Latifi (2010) suggested that ICF led to better improvement in students' written accuracy than direct feedback treatment. The results came from a study on 60 preintermediate English learners from an Iranian private English center comparing the effect of error correction and error detection along with the codes on the improvement of learners' writing accuracy of using vocabulary, grammar, organizational aspects and mechanics.

Chandler's (2003) research challenged the results and found both DCF and underlining of errors only to be more helpful than describing the type of error in increasing long-term accuracy. In her study, Chandler compared four types of feedback: direct correction, underlining with description, description only, and underlining only. Moreover, direct correction was rated as more preferable by the respondents of the survey results because of being the easiest and fastest way for revision of their grammatical errors, yet they thought that underlining the errors only led to better self-correction.

Overall, although these research studies have made contribution to the effect of CF and differential role of types of $\mathrm{CF}$, further studies need to address the effect of direct correction and indirect feedback (underlining with codes) on the various types of errors. Furthermore, it deems necessary to provide more clear-cut evidence on the effectiveness of error feedback on improvement of learners' writing accuracy in order to bridge the gap between both lines of research. However, it could be argued based on the recent evidence provided that error correction is an important factor in improvement of the writing accuracy. This can disprove Truscott's claim that correction of errors should be abandoned in EFL/ESL writing classrooms because it is not beneficial and even harmful.
Thus, future studies in this area can provide more insights and conclusive argument for or against error correction, and until then the debate continues as to whether DCF or ICF improves students' written accuracy and enables learners to reduce errors in new pieces of writing (Ferris \& Roberts, 2001; Liu, 2008). Another frequently mentioned issue in previous studies is that little empirical research carried out on the role of DCF and ICF in eliminating different linguistic error types in EFL students' essay writing. The abovementioned reasons together with research-design limitation of some studies that lack of control group are the major factors that prompt this investigation.

The current paper tries to explore one of the effective strategies in teaching writing and especially the role of DCF and ICF in the improvement of students' written accuracy of vocabulary, grammar and mechanics in new pieces of writing. Though much research has been conducted on different dimensions of feedback in EFL contexts, there is still the need to investigate this issue in Kurdish EFL context. The purpose of current paper is to examine the role of direct vs. indirect teacher-written feedback on undergraduate EFL Kurdish students' writing in context of Kurdistan Region of Iraq. To accomplish this aim, the below research questions were suggested:

1. Does (direct or indirect) written corrective feedback have any short-term effects on overall writing accuracy of Kurdish EFL university students in new pieces of writing comparing to control group?

2. Does (direct or indirect) written corrective feedback have any long-term effects on overall writing accuracy of Kurdish EFL university students in new pieces of writing comparing to control group?

3. Are there any differential short- or long-term effects between the direct or indirect written corrective feedback on overall writing accuracy of Kurdish EFL university students?

\section{METHODOLOGY}

\subsection{Design}

This paper, using an experimental design of pre-test, post-test, and delayed post-test attempted to examine the development of Kurdish EFL students' written accuracy in the use of targeted grammatical, lexical and mechanical categories. Based on their homogeneity in the pre-test, the subjects were randomly put into three groups, i.e. two experimental groups (direct and indirect) and one control group. The first experimental group was provided with direct correction on their errors. The second experimental group received indirect feedback through underlining and coding their errors. Finally, the control group was given no corrective feedback at all.

The independent variable in the current study includes the kinds of treatment provided for the subjects, namely giving feedback in three manners: direct error correction, underlining with codes and providing neither correction nor underlining of errors (or no corrective feedback). However, the dependent variable stands for the impact of the treatment on the subjects' written accuracy. 


\subsection{Instrumentation}

For this study, the language testing in the form of pre-test, post-test and delayed post-test written assessment was designed drawing from writing samples of International English Language Testing System (IELTS) Academic Writing Module Task 2 to investigate the effects of CF on level of writing accuracy.

\subsection{Participants}

The participants of this study were 124 EFL Kurdish third-year university students in English Departments at Sulaimani University and Charmo University in Iraqi Kurdistan Region. Of these, 19 participants (10 from Charmo University and 9 from Sulaimani University) were excluded from the data possessing and analysis due to their missing of sessions or one of the pre-, post or delayed posttests of writing.

Thus, the remaining students who regularly attended the classes thereafter regarded as subjects in the experiment accounted for 105: 42 males and 63 females. The students were taking a compulsory course called "Essay Writing" run by the Department of English at each university for third year students. The third year students were chosen at each university to ensure that their language backgrounds were similar to each other, and they were supposed to have built a potential linguistic foundation over their past two college years (first and second years). The majority of the subjects were almost the same age ranging from 19 to 21 .

\subsection{Procedures and data analysis}

The students in the three groups were given four written tests in classes and revision sessions for eight consecutive weeks in which their errors were treated differently and their errors were then analyzed and recorded separately. DCF experimental group received direct error correction on their scripts. In this group, ICF experimental group was provided with indirect error correction involved underlining of errors and writing a code over the error to indicate the type of error without writing the correction for students, and no corrective feedback (NCF) group was treated as control group. Once the writing papers were handed in by the students and collected by the researcher, they were then checked and read carefully by the researcher who employed comprehensive (unfocused) approach of WCF on correcting errors relating to grammar, vocabulary and writing mechanics. Students' papers were given back to all the students the following week. Once they received them, the students were required to write a second draft based on the feedback given to their writing and they were collected again for correction.

All groups were provided with the same amount and time of instruction and teaching of writing by the researcher. Group 1 received direct written corrective feedback in their essays delivered to the teacher. In this group, the researcher corrected the students' writing errors and gave them the correct form for each intended error; and afterward, the checked essays were handed back to the participants in order for them to improve their following writings by understanding their errors and their corrected forms. Group 2 were provided with indirect corrective feedback.

The researcher in this group underlined the students' writing errors and wrote the error codes above them. The students were introduced and explained to the error codes at the beginning of the term by the researcher, but the corrected forms were not provided to them. These error codes were a clue to the kind of errors made by the group; for instance, wherever "wo" was provided above a phrase or a sentence, it indicated that there was a problem concerning the word order; or wherever "vt" was written above a word, it meant that an error of verb tense had occurred (See the appendix for the complete list of the error codes).

Thenceforth, the coded corrected scripts were returned to the participants of this group and they were required to redraft their writings by making correction and give back the revised essays enclosed with the original ones at the end of the sessions. All the students were requested to produce 250-word short essays whose topics revolved mainly around argumentative issues. All the targeted error types were detected or corrected in the two experimental groups without selecting specific errors for correction or detection.

The experiment lasted for eight weeks and two sessions per week. Altogether, each student writer was asked to produce at least four new essays that account for almost one every other week. Three tests conducted on week 1, 6 and 8 were chosen for data collection and analysis. At the last week, the students were asked to hand in a writing delayed post-test to examine the long term effect of direct and indirect $\mathrm{CF}$ treatment versus no treatment of the control group.

In the present research, the overall accuracy in writing was calculated by counting error-free linguistic units or combinations such as clauses, sentences or T-units. In other words, this approach measures accuracy by calculating "the number of error-free T-units per T-unit $(\mathrm{EFT} / \mathrm{T})$ or the number of error-free clauses per clause $(\mathrm{EFC} / \mathrm{C})$ " (Wolf-Quintero et al., 1998, p. 35) or "(EFT/TT)" by Polio (1997, p. 122). In order to apply either of these, particularly the error-free Tunit, it is a prerequisite to specify what represents an error i.e. what is considered an error and what is not.

Research studies (cf. Henry, 1996; Hirano, 1991; Homburg, 1984; Larsen and Freeman, 1978, 1983; Sharma, 1980) have defined what recognised an error, and often the decision relies on the researcher's preference (Wolf-Quintero et al., 1998, p. 35). Some researchers measure accuracy by counting all spelling, vocabulary, punctuation and morphosyntactic as errors (cf. Henry, 1996; Larsen-Freeman, $1978,1983)$. There are studies deemed all the above as errors excluding punctuation (cf. Homburg, 1984). Other studies considered merely grammatical and lexical faults as errors (cf. Mubarak, 2013) whereas studies (cf. Abedi \& Latifi, 2010) regarded vocabulary, grammar, organizational aspects and mechanics as errors.

This study also applied the error-free T-unit ratio developed by Wolfe-Quintero et al. (1998. P. 44) measuring accuracy by counting the total number of error-free T-units divided by the total number of T-units in a given piece of writing (EFT/T). Similar to other studies (cf. Hartshorn, 2008), all the scores gained from the pre-test, the posttest and delayed post-test writings were converted into percentages for convenience and uniformity. Therefore, the overall accuracy in light of this method was calculated as (EFT/T) multiplied by 100 . The statistical analyses were performed with JMP Software to compare the mean scores of the groups.

The focus of WCF was on sentence-level and local errors. Similar to Mubarak (2013) and Engber (1995), the feedback targeted the grammatical and lexical errors, but it also involved writing mechanics (spelling and punctuation). Drawing on the recent studies (cf. Ellis 
and Barkhuizen, 2005, p. 139), the present study analysed language accuracy through considering grammatical, lexical and mechanical errors because it provides a wider and more balanced picture of language use. Grammatical errors include tenses, prepositions, relative clauses, connectors, auxiliary verbs and word order, subjectverb agreement etc.., lexical errors involve wrong word choice and wrong word form errors, and mechanical Errors contain punctuation and spelling.

\section{FINDINGS}

The findings emerged from this study are reported following data analyses. It begins by presenting the results of the pre-test data analysis carried out to examine if the students' performances in the pretest were similar before the treatment started. Then the results of the analyses done to examine the research questions addressed in this study are also presented.

\subsection{Students' performance before treatment}

This chapter reports the results of data analyses. In order to examine the students' performance before treatment, the results of the pre-test were analyzed to check if there were any group performance differences before the start of the experiment. A one-way Analysis of Variance (ANOVA) (i.e. between-groups one-way ANOVA) was used to determine if there were any differences between ICF, DCF and NCF before the treatment started. Post hoc of means comparisons for the pre-test was used to determine if there were any statistically significant differences between their pretest scores.

Table 4.1: Means and Standard Deviations of the Pre-Tests

\begin{tabular}{|l|l|l|l|l|l|}
\hline Groups & No. & Mean & $\begin{array}{l}\text { Standard } \\
\text { Deviation }\end{array}$ & Lower 95\% & $\begin{array}{l}\text { Upper } \\
\mathbf{9 5 \%}\end{array}$ \\
\hline DCF & 36 & 30.5939 & 3.2381 & 24.171 & 37.017 \\
\hline ICF & 36 & 23.2758 & 3.2381 & 16.853 & 29.699 \\
\hline NCF & 33 & 28.7848 & 3.3821 & 22.076 & 35.493 \\
\hline
\end{tabular}

The results in Table 4.1 indicate that the mean scores of the pre-test among the groups (DCF, ICF, and NCF) are 30.5939, 23.2758 and 28.7848 respectively, and are not close to each other. However, in order to test whether there is any significant difference among the mean scores or not, One-way ANOVA was run to do a hypothesis test.

Table 4.2: One-way Analysis of Variance (One-way ANOVA)

\begin{tabular}{|l|l|l|l|l|l|}
\hline Source & DF & $\begin{array}{r}\text { Sum of } \\
\text { Squares }\end{array}$ & Mean Square & F Ratio & Prob > F \\
\hline Groups & 2 & 1041.416 & 520.708 & \multirow{2}{*}{1.3794} & 0.2564 \\
\hline Error & 102 & 38503.116 & 377.482 & & \\
\hline C. Total & 104 & 39544.532 & & & \\
\hline
\end{tabular}

As Table 4.2 shows, there are no significant differences between the means of the groups (NCF, ICF, and DCF) since the $(\operatorname{Prob}>\mathrm{F})=0.2564$ is larger than $\alpha=0.05$, which leads to accept the null hypothesis.

To illustrate more details, a post hoc multiple comparison technique was used.

Analysis of Variance was carried out to test whether or not the mean scores of the pre-test among the groups was equal or not.

H_ $0: \mu(\mathrm{NCF})=\mu(\mathrm{ICF})=\mu(\mathrm{DCF})$

H_0=Null Hypothesis

H_1:at least two of the means are different with each other

\section{Figure 4.1: Post hoc of Means Comparisons for Pre-test}

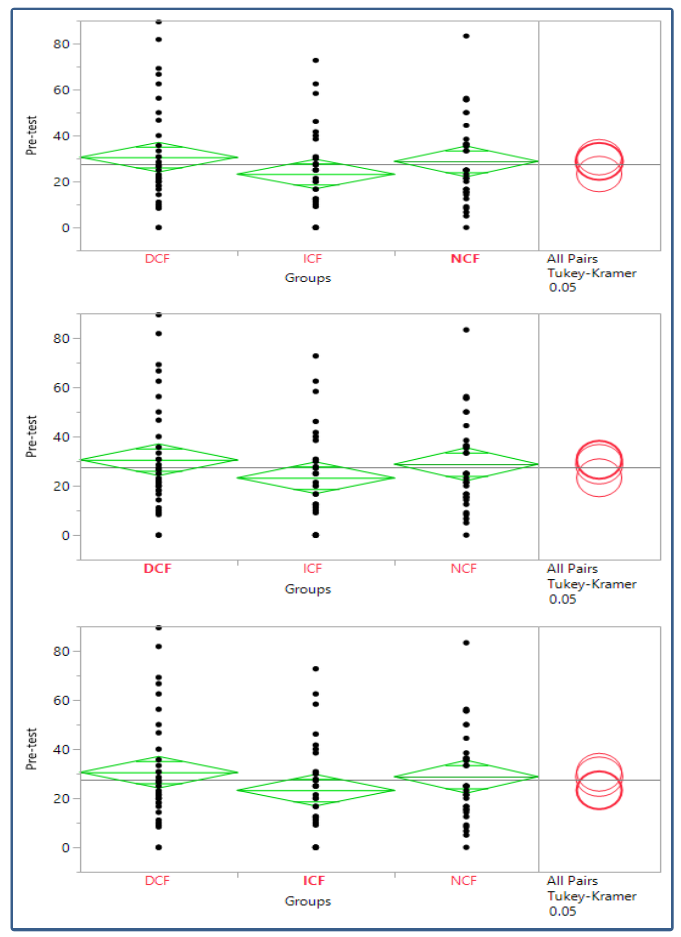

The results of Figure 4.1 illustrate that the mean for NCF is neither significantly different from the mean for ICF nor DCF, and the other groups show the same results. Therefore, no significant differences were found between any pairs of means among the groups.

\section{Table 4.3: Ordered Differences Report}

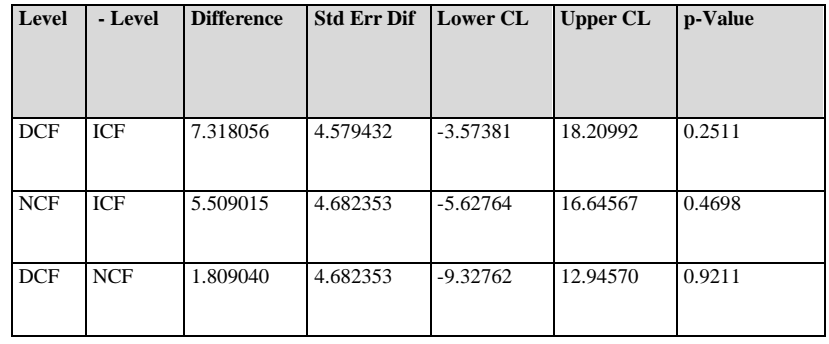

Table 4.3 indicates that the mean scores of CF and ICF are not significantly different due to its large p-value $=0.2511$. Additionally, the mean scores of NCF and ICF are not

JUHD | https://doi.org/10.21928/juhd. v4n4y2018.pp61-74 
significantly different while its $p-$ value $=0.4698$ and more than $\alpha=0.05$. Furthermore, since the p-value of the difference of the mean scores between DCF and NCF is large (0.9211), there is no significant difference between these two means. Thus, it can be said that the sample data of all the groups of NCF, ICF, and DCF have the same ability for the test.

\begin{tabular}{|l|l|l|}
\hline Overall Mean Scores & Pre-test & Short-term effect \\
\hline Groups & 26.9348611 & 35.6170833 \\
\hline Treatment & & \\
\hline Control & 28.7848485 & 27.3509091 \\
& & \\
\hline
\end{tabular}

\subsection{Short-term Effect of WCF on Students' Overall Written Accuracy after Treatment}

This section provides results about the investigation of the short-term effect of written corrective feedback (WCF) between the pre-test and post-test to ascertain if there was any improvement in students' written performance. Then the results of T-Unit ratio to measure students' overall written accuracy are explained below.

Figure 4.2: Overall Means between Pre-test and Shortterm Effects

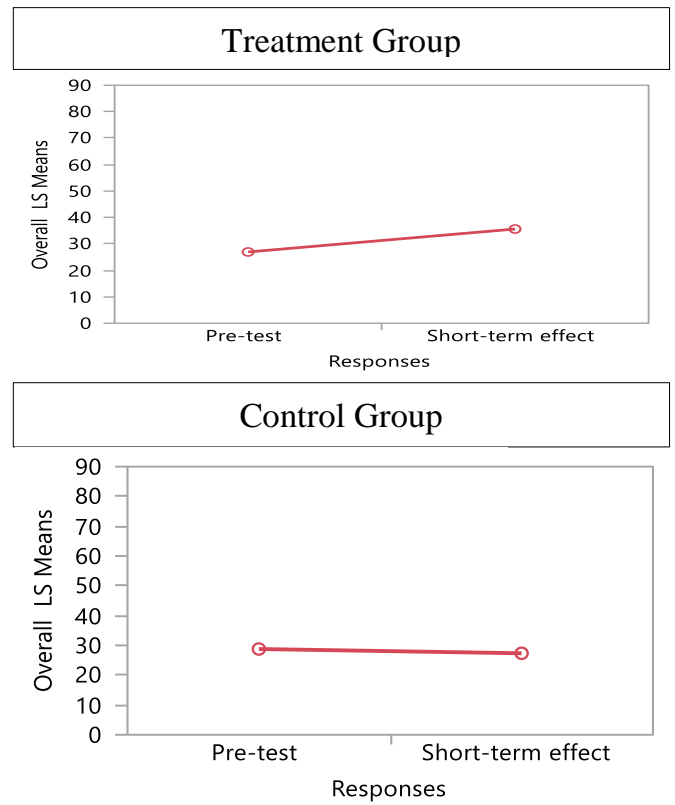

As Figure 4.2 and Table 4.4 indicate, the overall means of the treatment (corrective feedback) and control groups differ between the pre-test and post-test. It is clear that the overall mean score of corrective feedback group rises considerably in the post-test which shows a short-term effect (35.62) compared to the pre-test (26.93). In contrast, the overall mean score of the control group goes down to a lower level when it comes to the short-term effect (27.35), comparing to the pretest (28.78).

As this method measures accuracy by counting error-free Tunits, the findings reveal that students from the treatment group produced more accurate and error-free T-units (i.e. independent clauses together with all the dependent clauses attached to it), comparing to the control group. That is, it seems clear that the corrective feedback group performed better than the other group in producing error-free writing. To answer the research questions aiming to investigate the short-term effect of WCF on the students' written performance and which group was more effective, DCF, ICF and NCF groups' results were compared.

\section{Table 4.4: Overall Means between Pre-test and Short-term Effect}

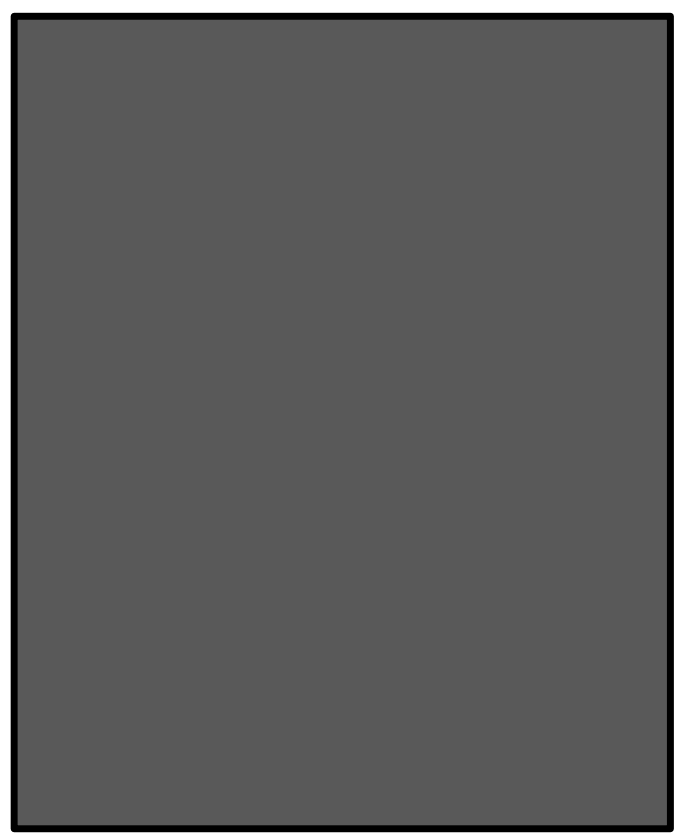

Figure 4.3: Overall Means of Groups (NCF, ICF, and DCF) between Pre-test and Short-term Effect

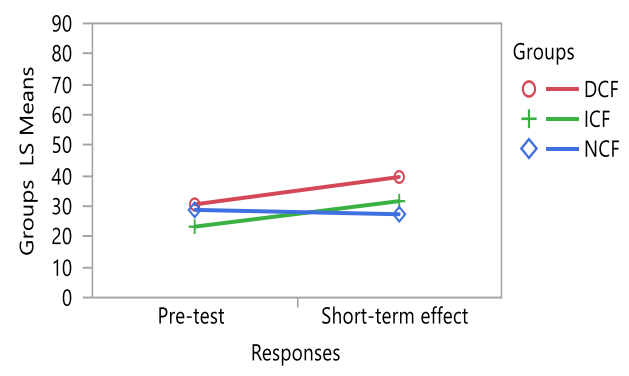

According to Figure 4.3 and Table 4.5, the mean score of the 
NCF group moves toward a lower level of the short-term effect compared to the pre-test in which the mean score of $\mathrm{NCF}$ in the short-term effect decreases by $\left(\frac{28.78-27.35}{28.78} * 100=\right.$ $4.97 \%)$

Table 4.5: Overall Means among groups between Pre-test and Short-term Effect

\begin{tabular}{|l|l|l|}
\hline Groups & Pre-test & Short-term Effect \\
\hline DCF & 30.5938889 & 39.5772222 \\
\hline ICF & 23.2758333 & 31.6569444 \\
\hline NCF & 28.7848485 & 27.3509091 \\
\hline
\end{tabular}

On the other hand, the mean scores of ICF and DCF rise in the post-test to an upper level of the short-term effect comparing to the pre-test, in which the mean score of ICF in the short-term effect increases by $\left(\frac{31.66-23.28}{31.66} * 100=\right.$ $26.47 \%$ ) in comparison with the mean score of ICF in the pre-test. Moreover, the mean score of DCF group in the shortterm effect grows by $\left(\frac{39.58-30.59}{39.58} * 100=22.71 \%\right)$. Hence, the largest amount of changes in the mean score from the pretest to short-term effect made by the ICF group and the smallest one made by the NCF group.

\subsection{Long-term Effect of WCF on Students' Overall Written Accuracy after Treatment}

It is evident from Figure 4.4 and Table 4.6 that

the overall means of the treatment (corrective feedback) and control groups are different between the pre-test and long-term effect. Further, it is clear that the overall mean score of corrective feedback group goes up largely in the long-term effect (42.72) comparing to the pre-test (26.93).

Figure 4.4: Overall Means between Pre-test and Longterm Effect

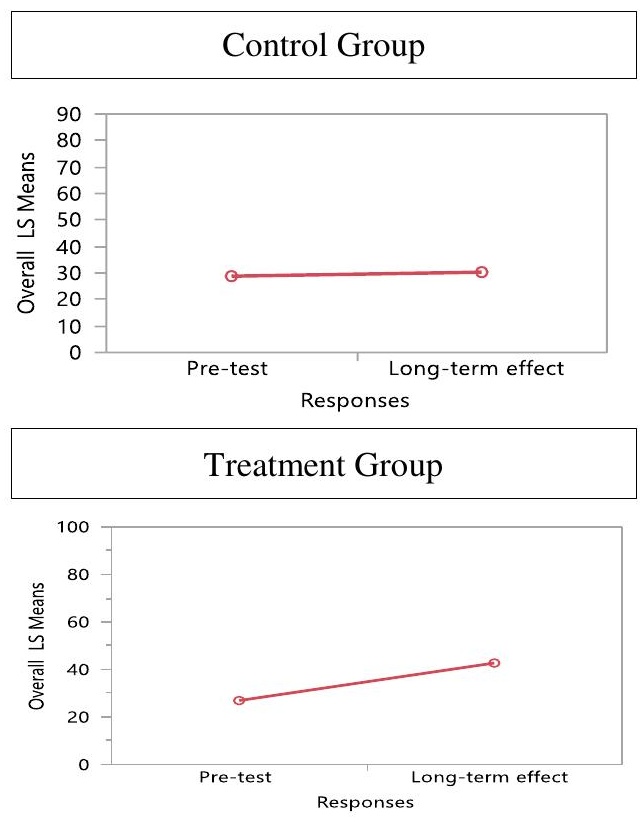

However, the overall mean score of the control group increases slightly in the long-term effect (30.31) in comparison with the pre-test (28.78). This clarifies that the treatment group made more improvement at the long-term phase than the control group in comparison with the pre-test. The following Figure 4.4 and Table 4.6 present the effectiveness of the mean scores among the groups within the pre-test and long-term effect.

Table 4.6: Overall Means between Pre-test and Long-term

\begin{tabular}{|l|l|l|}
\hline \multicolumn{2}{|l|}{ Overall Mean Scores } \\
\hline Groups & Pre-test & Long-term effect \\
\hline $\begin{array}{l}\text { Corrective } \\
\text { feedback }\end{array}$ & 26.9348611 & 42.7156944 \\
\hline Control & 28.7848485 & 30.3072727 \\
\hline
\end{tabular}

This clarifies that the treatment group made

more improvement at the long-term phase than the control group in comparison with the pre-test. The following Figure 4.4 and Table 4.6 present the effectiveness of the mean scores among the groups within the pre-test and long-term effect.

Figure 4.5: Overall Means of Groups (NCF, ICF, and DCF) between Pre-test and Long-term Effect

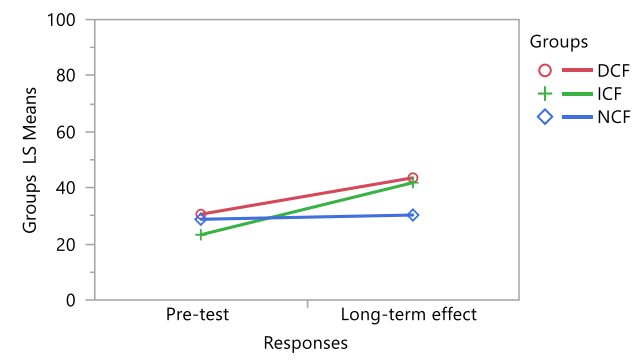

According to Figure 4.5 and Table 4.7, the mean scores of all the groups (NCF, ICF and DCF) goes towards an upper level in the long-term effect compared to the pre-test, in which the mean score of NCF group in the longterm effect increases by $\left(\frac{30.31-28.78}{30.31} * 100=\right.$ $5.05 \%$ ) compared to the NCF mean score of the pre-test, and the mean score of ICF in the long-term effect rises by $\left(\frac{41.84-23.28}{41.84} * 100=44.36 \%\right)$ compared to the ICF mean of the pre-test.

Table 4.7: Overall Means among groups between Pre-test and Long-term Effect

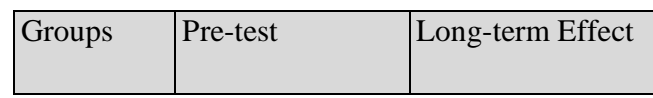

JUHD | https://doi.org/10.21928/juhd. v4n4y2018.pp61-74 


\begin{tabular}{|l|l|l|}
\hline Groups & Pre-test & Long-term Effect \\
\hline DCF & 30.5938889 & 43.5877778 \\
\hline ICF & 23.2758333 & 41.8436111 \\
\hline NCF & 28.7848485 & 30.3072727 \\
\hline
\end{tabular}

Besides, the mean score of DCF group in the long-term effect shows an increase by $\left(\frac{43.59-30.59}{43.59} * 100=\right.$ $29.82 \%)$.

Hence, it seems clear that the largest amount of changes in the mean score from the pre-test to long-term effect made by ICF group $(44.36 \%)$ and the smallest one by NCF group $(5.05 \%)$. As this method measures accuracy by counting errorfree T-units, the findings reveal that the students produced more accurate and error-free $\mathrm{T}$-units (i.e. independent clauses together with all the dependent clauses attached to it) in the delayed post-test. This demonstrates that the two treatment groups by far improved their written accuracy in the long-term more than the control group (NCF), and the ICF group outperformed the DCF group.

Figure 4.6: Figure of Overall Means between Pre-test, Short-term and Long-term Effects
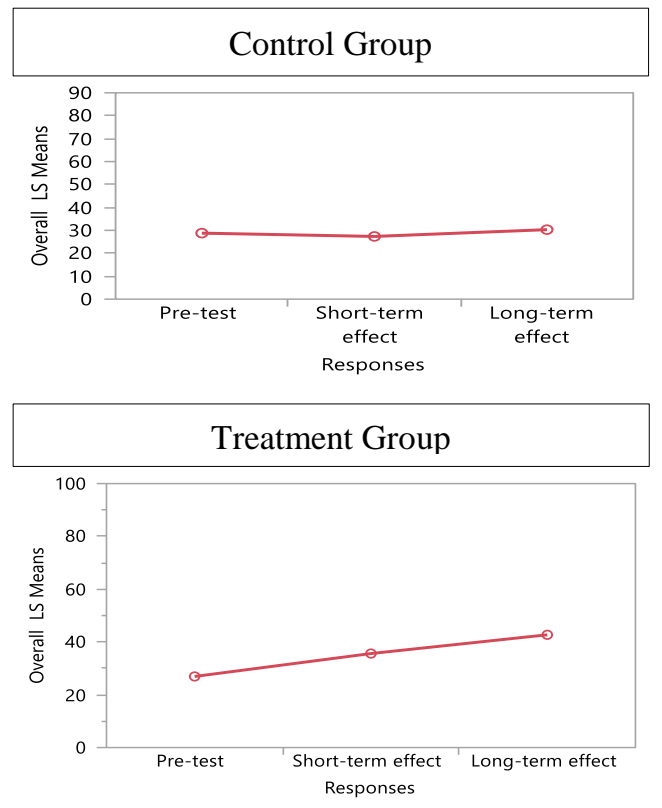

Now let's look at the results of the effectiveness of overall means of the short-term effect and long-term effect on the pretest.

Table 4.8: Overall Means between Pre-test, Short-term and Long-term Effects

$$
\text { Overall Mean Scores }
$$

JUHD | https://doi.org/10.21928/juhd. v4n4y2018.pp61-74

\begin{tabular}{|l|l|l|l|}
\hline Groups & Pre-test & $\begin{array}{l}\text { Short-term } \\
\text { effect }\end{array}$ & $\begin{array}{l}\text { Long-term } \\
\text { Effect }\end{array}$ \\
\hline Treatment & 26.9348611 & 35.6170833 & 42.7156944 \\
\hline Control & 28.7848485 & 27.3509091 & 30.3072727 \\
\hline
\end{tabular}

It is apparent from Figure 4.6 and Table 4.8

that the same results are found as explained before regarding the differences of the mean score between the three tests (pretest, post-test and delayed post-test). This illustrates that the lowest mean level of the treatment (corrective feedback) group goes towards the pre-test (26.93), and the biggest one is in the long-term effect.

On the other hand, for the control group, the

largest mean score goes up towards the long-term effect (30.31) and the lowest one is the short-term effect (27.35).

Figure 4.7 of groups (NCF, ICF, and DCF) among Pretest, Short-term Effect and Long-term

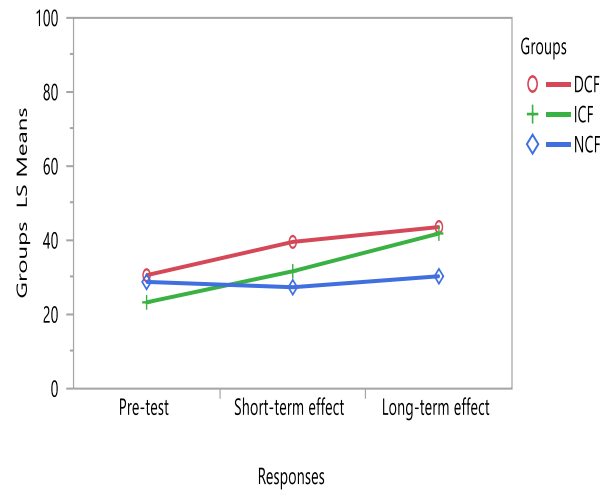

As Figure 4.7 and Table 4.9 show, all the groups display the lowest level of mean scores in the pre-test and the highest level of mean scores in the long-term effect. This shows the same results as explained before.

Table 4.9: Overall Means among groups between Pre-test, Short-term and Long-term Effects

\begin{tabular}{|l|l|l|l|}
\hline Groups & Pre-test & Short-term Effect & $\begin{array}{l}\text { Long-term } \\
\text { Effect }\end{array}$ \\
\hline DCF & 30.5938889 & 39.5772222 & 43.5877778 \\
\hline ICF & 23.2758333 & 31.6569444 & 41.8436111 \\
\hline NCF & 28.7848485 & 27.3509091 & 30.3072727 \\
\hline
\end{tabular}

However, the following tests determine

whether there is any statistically significant difference between the overall paired mean scores of (pre-test, short-term effect and long-term effect) regarding the first method, within groups (NCF, ICF, and DCF), and time between pre-test and short-term effect. 
Table 4.10: Repeated Measures of mixed ANOVA of the Pre-test, Short-term Effect, and Long-term Effect

\begin{tabular}{|l|l|l|l|l|l|}
\hline Tests & F-Value & $\begin{array}{l}\text { Exact } \\
\text { F }\end{array}$ & $\begin{array}{l}\text { NumD } \\
\text { F }\end{array}$ & $\begin{array}{l}\text { Den } \\
\text { DF }\end{array}$ & Prob>F \\
\hline $\begin{array}{l}\text { Between } \\
\text { Subjects }\end{array}$ & 0.0805869 & 4.1099 & 2 & 102 & $0.0192^{*}$ \\
\hline $\begin{array}{l}\text { Within } \\
\text { Groups }\end{array}$ & 0.0805869 & 4.1099 & 2 & 102 & $0.0192^{*}$ \\
\hline Time & 0.1750008 & 8.8375 & 2 & 101 & $0.0003^{*}$ \\
\hline $\begin{array}{l}\text { Time * } \\
\text { Groups }\end{array}$ & 0.0738121 & 3.7644 & 2 & 102 & $0.0265^{*}$ \\
\hline
\end{tabular}

As Table 4.10 shows, the overall paired mean scores between the pre-test, short-term effect and long-term effect are significantly different since its p-value $=0.0192$. In addition, the p-value of Within Groups $=0.0192$, and this indicates that the difference in the mean scores among groups NCF, ICF, and DCF are statistically significant. Moreover, Time factor between pre-test and long-term effect is statistically significant because of its small p-value $=0.0001$.

Furthermore, the interaction factor between

Time and Groups (Time * Groups) is significant too since its p-value smaller than $\alpha=0.05$.

Now we put all the data from the different tests

(pre-test, short-term effect, and long-term effect) into one group and it was subject to analysis by using one-way ANOVA to see if there was any significant difference between the pre-test and short-term effect, also between the pre-test and long-term test in accordance with the first method.

Table 4.11: Overall Means and Standard Deviations for (Pre-test, Short-term Effect, and Long-term Effect)

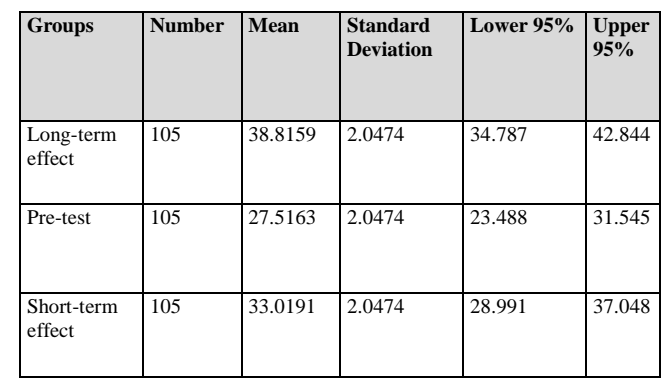

The results obtained about the difference in the

overall mean of the pre-test (27.5163) from the overall means of long-term effect (38.8159) and short-term effect (33.0191) can be compared in Table 4.11. On the other hand, the mean of the long-term effect is different from the short-term effect. Furthermore, the standard deviations of all the groups are equal. However, a one-way ANOVA was used to reveal any significant differences between the means of the groups as shown in the following table.

Table 4.12: One-way Analysis of Variance (One-way ANOVA) for Pre-test, Short-term Effect and Long-Term Effect

\begin{tabular}{|l|l|l|l|l|l|}
\hline Source & DF & $\begin{array}{l}\text { Sum of } \\
\text { Squares }\end{array}$ & $\begin{array}{l}\text { Mean } \\
\text { Square }\end{array}$ & F Ratio & Prob > F \\
\hline Groups & 2 & 6704.78 & 3352.39 & \multirow{2}{*}{7.6163} & $0.0006^{*}$ \\
\hline Error & 312 & 137330.39 & 440.16 & & \\
\cline { 1 - 4 } C. Total & 314 & 144035.17 & & & \\
\hline
\end{tabular}

From Table 4.12, a one-way ANOVA was applied to test if the overall means among the group tests of (pre-test, short-term effect, and long-term effect) were significantly different with each other.

$H_{0}: \mu($ pre - test $)=\mu($ short - term effect $)=$ $\mu($ long - term effect $)=0$

$H_{1}$ : at least two of the means

are different with each other

The differences between at least two of the

means are highlighted in Table 4.12 because the results indicate that the (Prob $>\mathrm{F})=0.0006$ is smaller than $\alpha=$ 0.05 , which rejected the null hypothesis $H_{0}$. Post hoc multiple comparison technique and order difference report were used to reveal which means were different.

\section{Figure 4.8: Post hoc of Overall Means Comparisons for (Pre-test, Short-term, and Long-term)}
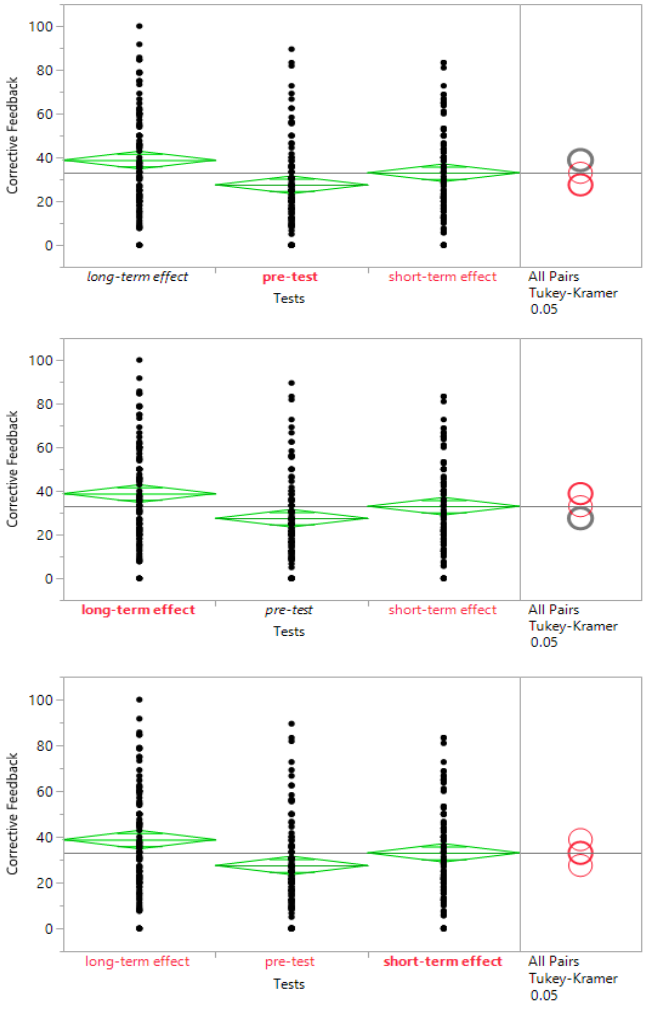

As can be seen from Figure 4.8, the overall means of the pre-test are significantly different from the overall means of the long-term effect. On the other hand, there are not any significant differences between the groups in terms 
of pairs of overall means of the short-term effect and longterm effects.

\section{DISCUSSION}

The current paper tried to investigate the effect of two different types of feedback on the writing accuracy of undergraduate students concerning grammatical, lexical and mechanical errors. In line with Ferris $(1999,2002)$, students who were provided with written corrective feedback achieved better linguistic accuracy on new writing tasks than those in the control group for both short- and long terms. Because several factors paly a role in improving students' overall linguistic accuracy (such as: teacher and learner's attitude toward correction, the method of teaching, and the method used for error correction), it is difficult to say which method of corrective feedback is the best.

However, this study showed that the overall writing accuracy of the participants received indirect corrective feedback performed significantly better improvement in their accuracy compared with those who were provided with direct corrective feedback for both short- and long terms. In line with Ferris (2002), the present study has a tentative evidence that error correction is mainly considered by writing instructors as a crucial teaching tool for writing development and widely expected and welcomed by ESL/EFL learners.

On the other hand, the results obtained from this paper were in disagreement with Truscott's claim based on a review of studies by Kepner (1991), Semke (1984), and Sheppard (1992) arguing that corrective feedback has a negative role in improving learners' writing accuracy. The results of this study question Truscott's claim based on these few number of studies by investigating the short- and long term effect of two types of feedback on students' accuracy in new pieces of writing.

To address the gap, the findings of the current research cautiously support the effectiveness of corrective feedback on students' writing accuracy (Ferris, 1997; Chandler, 2003; Bitchener, 2008; Bitchener et al 2005; Abedi \& Latifi, 2010; Hosseiny, 2014; Shintani, Ellis \& Suzuki, 2014; Eslami, 2014). Furthermore, it can be argued that the results also invalidate Truscott's idea questioning the long term effect of error feedback as the treatment group has shown significant improvement compared to their control group, though the long term effect of indirect feedback is more than the direct feedback.

The current research has also shown that the type of feedback provided had a significant effect on the students' writing improvement. It was found that those students who received indirect feedback on their scripts through underlining of errors along with codes, made better achievement in reducing the amount of errors while producing new pieces of writing. In other words, they benefited from this type of feedback more than the direct feedback. Thus, the results of this paper appear to corroborate the argument for indirect feedback as opposite to the direct feedback (Ferris, 2003; Abdi \& Latifi, 2010; Eslami, 2014; Jamalinesari, Rahimi, Gowhary \& Azizifar, 2015) through demanding the students to engage and give more attention to correcting the errors. Moreover, it can be said that the reason for

more efficacy of indirect feedback through locating and providing codes for them would be causing more reflection on writings similar to consciousness raising task (Ellis, 2003) that allowed more encouragement and independency. It could be argued that students just take a superficial look when they receive direct errors correction and they make less efforts to learn about their errors, but when their errors are only underlined, they had to think and search for their correct forms by themselves hereafter, they would learn from this better.

Hence, detecting errors can be seen as a complementary strategy to implicit teaching of linguistic features in order for students to obtain an ultimate level of improvement in their written accuracy (Jamalinesari, Rahimi, Gowhary \& Azizifar, 2015). It may also address the issue of effectively filtering students' development in language acquisition (Krashen, 2003) caused by direct error correction.

This paper has implications for writing tutors. It suggests that teachers should consider students' practice in such writing assessment so that they can determine better curriculum and teaching in a way that boosts students' ability in writing. In spite of the research questions answered in this paper, there are still other questions that have to be investigated in future research such as considering students' views on corrective feedback types in writing, whether the effect of error feedback vary according to error types, and individual differences.

\section{CONLUSION}

This study was conducted to compare the usefulness of two types of WCF i.e. direct and indirect corrective feedback on developing students' writing accuracy in both short-term and long-term. Contrary to Truscott's $(1996,2007)$ claim that corrective feedback has negative effect on the learners' ability to write accurately, the conclusion can be drawn from this study is that when WCF is targeted at a rang of errors (comprehensive) and is provided consistently, it has a great beneficial effect on the improvement of EFL students' accuracy over time. It can also be concluded that ICF group proved to be largely better than the DCF group in the long term.

Thus, the findings of this paper have pedagogical implications on how explicit the CF should be given, and the extent to which students attend to CF. In this study, the provision of WCF on frequent occasions can increase students' writing proficiency level over the intended errors. Most importantly, it may be recommended that writing instructors offer comprehensive (unfocused) feedback on multiple sentencelevel errors when the aim of teaching is to develop linguistic accuracy. Finally, it is hoped that this investigation will provoke more research about the effects of DCF and ICF on improving of students' writing accuracy in EFL contexts.

\section{AKNOWLEDGEENT}

The authors thank the anonymous reviewers for their valued comments on the drafts of this paper. They also thank the teaching staff and students from Sulaimani University and 
Charmo University for their contribution to this study supported and supervised by the English Department, College of Basic Education at Sulaiman University.

\section{REFERENCES}

Abedi, R., \& Latifi, M. (2010). The effect of error correction vs. error detection on Iranian pre-intermediate EFL learners' writing achievement. English Language Teaching, 3(4), 168.

Alimohammadi, B., \& Nejadansari, D. (2014). Written corrective feedback: focused and unfocused. Theory and Practice in Language Studies, 4(3), 581.

Almasi, E., \& Tabrizi, A. R. N. (2016). The effects of direct vs. indirect corrective feedback on Iranian EFL learners' writing accuracy. Journal of Applied Linguistics and Language Research, 3(1), 74-85.

Bitchener, J. (2008). Evidence in support of written corrective feedback. Journal of Second Language Writing, 12, 102-118.

Bitchener, J., \& Knoch, U. (2008). The value of written corrective feedback for migrant and international students. Language Teaching Research, 12, 409-431.

Bitchener, J., \& Knoch, U. (2010). Raising the linguistic accuracy level of advanced L2 writers with written corrective feedback. Journal of Second Language Writing, 19, 207-217.

Bitchener, J., Young, S., \& Cameron, D. (2005). The effect of different types of corrective feedback on ESL student writing. Journal of Second Language Writing, 14(3), 191-205.

Bower, J., \& Kawaguchi, S. (2011). Negotiation of meaning and corrective feedback in Japanese/English eTandem. Language Learning \& Technology, 15(1), 41-71. Retrieved from http://llt.msu.edu/issues/february2011/bowerkawaguchi.pdf

Bruton, A. (2010). Another reply to Truscott on error correction: Improved situated designs over statistics. System, 38(3), 491498.

Chandler, J. (2003). The efficacy of various kinds of error feedback for improvement in the accuracy and fluency of L2 student writing. Journal of second language writing, 12(3), 267-296.

Diab, N. M. (2015). Effectiveness of written corrective feedback: Does type of error and type of correction matter?. Assessing Writing, 24, 16-34.

Ellis, R. (2003). Task-based language

learning and teaching. Oxford: Oxford University Press.

Ellis, R. \& Barkhuizen, G. (2005). Analysing Learner Language. Oxford: Oxford University Press.

Engber, C. A. (1995). The relationship of lexical proficiency to the quality of ESL compositions. Journal of Second Language Writing, 4(2), 139-155.
Eslami, E. (2014). The effects of direct and indirect corrective feedback techniques on EFL students' writing. Procedia-Social and Behavioral Sciences, 98, 445-452.

Ferris, D. (1997). The influence of teacher commentary on student revision. TESOL Quarterly, 31, 315-339.

Ferris, D. (1999). The case for grammar correction in L2 writing classes: A response to Truscott(1996). Journal of Second Language Writing, 8(1), 1-11.

Ferris, D. (2002). Treatment of error in second language student writing. Ann Arbor: University of Michigan Press.

Ferris, D. (2004). The "grammar correction" debate in L2 writing: Where are we, and where do we go from here? (and what do we do in the meantime ...?). Journal of Second Language Writing, $13,49-62$.

Ferris, D. (2011). Treatment of error in second language student writing. The Michigan Series on Teaching Multilingual Writers: University of Michigan Press.

Ferris, D. R. (2010). Second language writing research and written corrective feedback in SLA: Intersections and practical applications. Studies in Second Language Acquisition, 32(2), 181-201.

Ferris, D., \& Roberts, B. (2001). Error feedback in L2 writing classes: How explicit does it need to be?. Journal of Second Language Writing, 10(3), 161-184.

Hama, F. M. \& Ismael, D. A. (2018). The effects of teacher's corrective feedback on Kurdish EFL undergraduate students' redraft essays. Journal of Education and Practice, 9(7), 61-66.

Hartshorn, K. J. (2008). The effects of manageable corrective feedback on ESL writing accuracy (Doctoral thesis). Brigham Young University. Retrieved from BYU ScholarsArchive at https://scholarsarchive.byu.edu/cgi/viewcontent.cgi?referer $=\&$ h ttpsredir $=1 \&$ article $=2521 \&$ context $=$ etd.

Hendrickson, J. M. (1978). Error correction in foreign language teaching: Recent theory, research, and practice. The Modern Language Journal, 62, 387-398.

Henry, K. (1996). Early L2 writing development: a study of autobiographical essays by university-level students of Russian. The Modern Language Journal, 80, 309- 326.

Hirano, K. (1991). The effect of audience on the efficacy of objective measures of EFL proficiency in Japanese university students. Annual Review of English Language Education in Japan, 2, 21 30.

Homburg, T. J. (1984). Holistic evaluation of ESL compositions: can it be validated objectively? TESOL Quarterly, 18, 78-107.

Hong, Y. (2004). The effect of teachers' error feedback on international students' self-correction ability (Master's thesis). Retrieved from https://scholarsarchive.byu.edu/cgi/viewcontent.cgi?referer=htt ps://www.google.com $/ \&$ httpsredir $=1 \&$ article $=1182 \&$ context $=$ et d

JUHD | https://doi.org/10.21928/juhd. v4n4y2018.pp61-74 
Hosseiny, M. (2014). The role of direct and indirect written corrective feedback in improving Iranian EFL students' writing skill. Procedia-Social and Behavioral Sciences, 98, 668-674.

Hyland, F. (2003). Focus on form: Student engagement with teacher feedback. System, 31, 217-30.

Jamalinesari, A., Rahimi, F., Gowhary, H., \& Azizifar, A. (2015). The Effects of Teacher-Written Direct vs. Indirect Feedback on Students' Writing. Procedia-Social and Behavioral Sciences, 192, 116-123.

Kang, E., \& Han, Z. (2015). The efficacy of written corrective feedback in improving L2 written accuracy: A meta-analysis. The Modern Language Journal, 99(1), 1-18.

Kepner, C. G. (1991). An experiment in the relationship of types of written feedback to the linguistic accuracy on essay revisions. Journal of Second Language Writing, 7, 43-68.

Krashen, S. (2003). Explorations in Language Acquisition and Use: The Taipei Lectures. Portsmouth, NH: Heinemann.

Lane, J. and Lange E. (2012). Writing Clearly: Grammar for Writing. USA: Sherrise Roehr.

Larsen-Freeman, D. (1978). An ESL index of development. TESOL Quarterly, 12, 439- 448.

Larsen-Freeman, D. (1983). Assessing global second language proficiency. In H. W. Seliger and M. Long (Eds.), Classroomoriented research in second language acquisition (pp. 287304). Rowley, MA: Newbury House.

Lee, Icy. (2005). Error correction in L2 secondary writing classroom: The case of Hong Kong. Journal of Second Language Writing, 13, 285-312. https://doi.org/10.1016/j.jslw.2004.08.001

Liu, Q., \& Brown, D. (2015). Methodological synthesis of research on the effectiveness of corrective feedback in L2 writing. Journal of Second Language Writing, 30, 66-81.

Liu, Y. (2008). The effects of error feedback in second language writing. The Arizona Working Papers in Second Language Acquisition and Teaching, 15, 65-79.

Mubarak, M. (2013). Corrective feedback in L2 writing: A study of practices and effectiveness in the Bahrain context (Doctoral dissertation, University of Sheffield).

Polio, C. (2012). The relevance of second language acquisition theory to the written error correction debate. Journal of Second Language Writing, 21(4), 375-389.

Polio, C. G. (1997). Measures of linguistic accuracy in second language writing research. Language learning, 47(1), 101-143.

Polio, C., Fleck, C., \& Leder, N. (1998). "If only I had more time'” ESL learners' changes in development of second-language writing skills. The Modern Language Journal, 75, 305-313.

Russell, J., \& Spada, N. (2006). The effectiveness of corrective feedback for the acquisition of L2 grammar: A meta-analysis of the research. In J. Norris \& L. Ortega (Eds.), Synthesizing

JUHD | https://doi.org/10.21928/juhd. v4n4y2018.pp61-74
Research on Language Learning and Teaching. Amsterdam: Benjamins. 133-164.

Semke, H. (1984). The effects of the red pen. Foreign Language Annals, 17, 195-202.

Sharma, A. (1980). Syntactic maturity: assessing writing proficiency in a second language. In. R. Silverstein (Ed.), Occasional Papers in Linguistics, 6, 318-325.

Sheppard, K. (1992). Two feedback types: Do they make a difference? RELC Journal, 23, 103-110.

Shintani, N., Ellis, R., \& Suzuki, W. (2014). Effects of written feedback and revision on learners' accuracy in using two English grammatical structures. Language Learning, 64(1), 103-131.

Tootkaboni, A. A., \& Khatib, M. (2014). The Efficacy of Various Kinds of Error Feedback for Improvement in the Writing Accuracy of Iranian EFL Learners. Bellaterra Journal of Teaching \& Learning Language \& Literature, 7(3), 30-46.

Truscott, J. (1996). The case against grammar correction in L2 writing classes. Language Learning, 46(2), 327-369.

Truscott, J. (1999). The Case for "The Case Against Grammar Correction in L2 Writing Classes": A Response to Ferris. Journal of Second Language Writing, 8(2), 111-122.

Truscott, J. (2004). Evidence and Conjecture on the Effects of Correction: A Response to Chandler. Journal of Second Language Writing, 13, 337- 343.

Truscott, J. (2007). The effect of error correction on learners' ability to write accurately. Journal of Second Language Writing, $16(4), 255-272$.

Wang, X. (2017). The Effects of Corrective Feedback on Chinese Learners' Writing Accuracy: A Quantitative Analysis in an EFL Context. World Journal of Education, 7(2), 74.

Wolfe-Quintero, K., Inagaki, S., \& Kim, H. Y. (1998). Second language development in writing: Measures of fluency, accuracy, \& complexity (No. 17). University of Hawaii Press.

Zamel, V. (1985). Responding to student writing. TESOL Quarterly, $19,79-101$ 
APENDIX

Errors categories and correction symbols, adapted from Lane \& Lange (2012), pp. 338-342.

\begin{tabular}{|l|l|l|}
\hline No & Error Categories & $\begin{array}{l}\text { Error } \\
\text { Symbols }\end{array}$ \\
\hline $\mathbf{A}$ & Grammatical Errors & frag \\
\hline $\mathbf{1}$ & fragment & ro \\
\hline $\mathbf{2}$ & run on & ps \\
\hline $\mathbf{3}$ & parallel structure & rc \\
\hline $\mathbf{4}$ & relative clause & wo \\
\hline $\mathbf{5}$ & word order & vt \\
\hline $\mathbf{6}$ & verb tense & vf \\
\hline $\mathbf{7}$ & verb form & mod \\
\hline $\mathbf{8}$ & Modals & pass \\
\hline $\mathbf{9}$ & passive & conn \\
\hline $\mathbf{1 0}$ & connector & s/p \\
\hline $\mathbf{1 1}$ & singular or plural & s/v agr \\
\hline $\mathbf{1 2}$ & subject-verb agreement & c/s \\
\hline $\mathbf{1 3}$ & comparative/superlative forms & poss \\
\hline $\mathbf{1 4}$ & possessives & det \\
\hline $\mathbf{1 5}$ & Determiner & art \\
\hline $\mathbf{1 6}$ & Article & pre \\
\hline $\mathbf{1 7}$ & Preposition & pro \\
\hline $\mathbf{1 8}$ & Pronoun & pro agr \\
\hline $\mathbf{1 9}$ & pronoun agreement & pro \\
\hline $\mathbf{2 0}$ & pronoun reference ref & ss \\
\hline $\mathbf{2 1}$ & sentence structure & \multicolumn{2}{|l|}{} \\
\hline $\mathbf{B}$ & Lexical Errors & wc \\
\hline $\mathbf{2 2}$ & word choice & wf \\
\hline $\mathbf{2 3}$ & word form & p \\
\hline $\mathbf{C}$ & Mechanical Errors & sp \\
\hline $\mathbf{2 4}$ & Punctuation & \multicolumn{2}{|l|}{} \\
\hline $\mathbf{2 5}$ & Spelling & $\mathbf{2}$ \\
\hline & & $\mathbf{2}$ \\
\hline
\end{tabular}

